\title{
Histeria e psiquiatria no Brasil da Primeira República
}

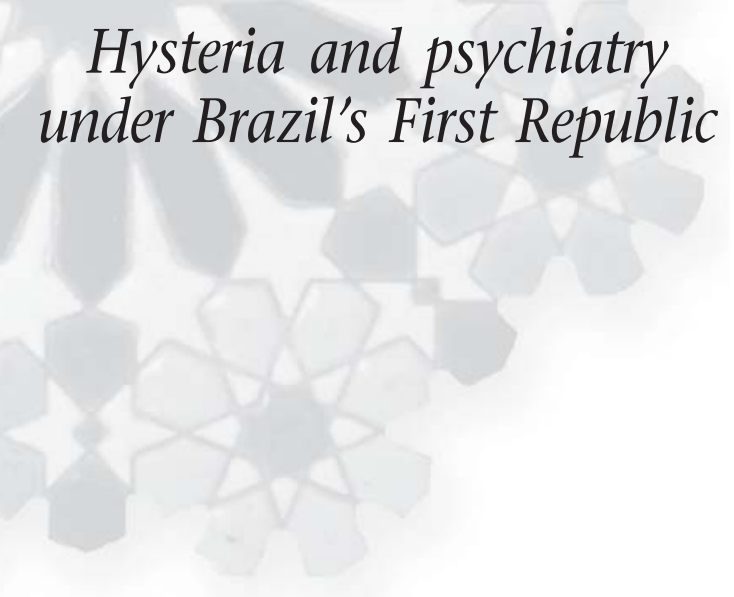

Sílvia Alexim Nunes

Médica, psicanalista; pesquisadora do grupo Epos - Genealogias, Subjetivações e Violências/Instituto de Medicina Social/Universidade do Estado do Rio de Janeiro.

Rua Cedro, 159

22451-320 - Rio de Janeiro - RJ - Brasil silviaalexim@uol.com.br

Recebido para publicação em fevereiro de 2010. Aprovado para publicação em setembro de 2010.

NUNES, Sílvia Alexim. Histeria e psiquiatria no Brasil da Primeira República. História, Ciências, Saúde Manguinhos, Rio de Janeiro, v.17, supl.2, dez. 2010, p.373-389.

Resumo

Problematiza o pensamento psiquiátrico brasileiro sobre a histeria nas primeiras décadas do século XX, momento de expansão de uma medicina social que se constituiu no bojo de uma biopolítica de gestão populacional. Para isso, esse pensamento é inserido no debate sobre a histeria nos grandes centros europeus no século XIX e que foi referência para a nascente psiquiatria brasileira dentro de um projeto reformador e preventivista que caracterizou a medicina brasileira da época. São abordados o trabalho do neurologista brasileiro Antônio Austregésilo (18761960), sua inserção nesse projeto e seu lugar no processo de desmembramento da histeria como categoria diagnóstica, no campo da psiquiatria, o que se deu ao longo da República Velha.

Palavras-chave: histeria; biopoder; psiquiatria; Antônio Austregésilo (1876-1960); Brasil.

\section{Abstract}

The article problematizes Brazilian psychiatric thought on hysteria in the early decades of the twentieth century, a time when a biopolicy of population management was lending impetus to the growth of social medicine. This notion is situated within the context of the nineteenth-century debate on hysteria that took place in major European centers and served as the main reference for Brazil's fledgling field of psychiatry. The debate found expression in Brazilian psychiatric discourse as part of the era's project for medical reform and prevention in Brazil. The work of Brazilian neurologist Antônio Austregésilo (1876-1960) within this project is also addressed, since he played a fundamental role in dismantling hysteria as a diagnostic category in psychiatry, a process that continued through the entire Old Republic.

Keywords: hysteria; biopower; psychiatry; Antônio Austregésilo (1876-1960); Brazil. 

questão da histeria está em vias de ser resolvida". Com esta afirmação, o médico Antônio Austregésilo (1876-1960) inicia seu artigo "Histeria e síndrome histeroide", publicado em 1909. Tal colocação ressalta o quanto a histeria representava um problema para a medicina na passagem do século XIX para o XX.

Na segunda metade do século XIX, a histeria era um dos principais campos de interesse psiquiátrico e neurológico. Apresentava-se como um certo enigma para uma medicina que se constituiu em torno de uma racionalidade que associava o surgimento da doença à lesão localizada no corpo do doente. Com efeito, a medicina ocidental moderna que se instaurou a partir do século XIX caracterizou-se por uma racionalidade na qual o conjunto de sinais e sintomas dos enfermos foi associado a lesões dos órgãos e tecidos, passando os achados anatomopatológicos a ser considerados o fundamento do saber clínico e da condição de diagnóstico (Foucault, 1977a). A histeria, que se manifestava por uma variedade infinita de sintomas corporais, colocava um problema para essa medicina somática, que não conseguia relacionar tais sintomas a lesões anatômicas ou histológicas específicas.

No pensamento médico, dois pontos fundamentais estavam em pauta com relação à histeria. O primeiro era a dificuldade encontrada para enquadrá-la nos sistemas classificatórios da época. Os discursos médicos procuravam de forma insistente descrever e circunscrever uma doença que se apresentava de forma polimorfa e ruidosa, dificultando sua apreensão, a um quadro nosográfico específico. O segundo ponto nevrálgico era a intensa discussão sobre sua etiologia, que tinha como pano de fundo a assimilação da histeria ao sexo feminino. Tal discussão se desdobrava em reflexão sobre a natureza feminina.

Eram essas as questões debatidas pelos médicos da transição para o século XX, momento em que Antônio Austregésilo se voltou para o estudo da histeria. Essas questões ocuparam os expoentes da psiquiatria e da neurologia brasileiras, que aqui reproduziram os debates então travados nos grandes centros médicos europeus no início do século XVII e que resultaram nas primeiras fraturas na concepção de histeria originada na Antiguidade, hegemônica até então.

\section{A pré-história das concepções médicas sobre histeria}

A noção de histeria aparece no século IV a.C. com Hipócrates que, voltando sua atenção para o estudo das doenças das mulheres, formulou a noção de "sufocação da matriz ou hystero". Retomou assim a ideia, presente no antigo Egito, de que o útero, ou hystero, seria um organismo vivo, análogo a um animal, dotado de certa autonomia e de possibilidade de deslocamento. Em sua opinião, a mobilidade do útero no interior do corpo explicaria muitas doenças femininas, incluída a sufocação da matriz. Ao se deslocar, o útero se poderia fixar sobre outros órgãos causando ansiedade, tonturas, vômitos, dores de cabeça e pescoço, resfriamento das pernas, perda da palavra. Uma sintomatologia polimorfa, imprevisível, suscetível de atingir todas as partes do corpo e suas grandes funções (Cattoné, 1992).

N.E. - O presente artigo é uma reflexão crítica baseada em texto de Antônio Austregésilo, "Histeria e síndrome histeroide", reproduzido neste número de História, Ciências, Saúde - Manguinhos. 
Segundo Hipócrates, a histeria era doença feminina, derivada da ausência de relações sexuais. Alinhando-se a Hipócrates, Platão reforçou a analogia do útero com um ser vivo propondo que esses deslocamentos seriam determinados por um desejo de fazer crianças (Cattoné, 1992). Portanto, desde a tradição grega a histeria foi formulada como uma questão própria das mulheres, ligada à insatisfação sexual ou ao desejo de procriar. Nessa concepção, as mulheres teriam uma espécie de fome de gerar, que definiria seu ser (Birman, 2001), perspectiva segundo a qual a hipótese de histeria masculina era impensável.

Essa concepção da histeria atravessou toda a Antiguidade. Durante a Idade Média, a tese da sufocação da matriz desapareceu, e as convulsões e outras manifestações corporais foram atribuídas à possessão diabólica e à bruxaria, transformando-se em assunto de padres e inquisidores (Trillat, 1991).

\section{A histeria e a questão feminina}

A histeria só ressurgiu nos discursos médicos no século XVII, ganhando destaque com a teoria dos vapores proposta por Lange ${ }^{1}$ que, em 1689, restabeleceu sua etiologia uterina. No entanto, nesse mesmo momento apareceram os primeiros questionamentos à associação direta entre histeria e aparelho reprodutor feminino. Thomas Willis $(1621-1675)^{2}$ e Thomas Sydenham (1624-1689) ${ }^{3}$ eram as figuras de proa na defesa da tese de que a sede da histeria seria o cérebro. Rompendo com a tradição grega, eles articularam teorias que tornavam concebível a histeria em homens.

A partir de então, os médicos se dividiram entre os partidários da tese de que a etiologia da histeria estaria nos órgãos reprodutores femininos, e os que defendiam que a histeria teria origem em disfunções do sistema nervoso, ou seja, uma etiologia neurológica. No entanto, é interessante observar dois pontos importantes. O primeiro é que a teoria dos vapores, embora remetesse a histeria a uma patologia uterina, não supunha o deslocamento da matriz pelo corpo. Com isso, precisou explicar de que forma os vapores acumulados no útero se difundiriam pelo organismo causando os diferentes sintomas. Conforme a hipótese formulada por Lange, os vapores subiriam para o cérebro pelo "canal dos nervos" provocando a sintomatologia histérica. Portanto, apesar de sustentar a etiologia uterina, ao descrever as formas de propagação dos vapores produzidos na matriz pelo corpo atribuiu aos nervos papel fundamental. Seria a transmissão dos vapores através dos nervos que possibilitaria a configuração polimórfica e disseminada da histeria (Trillait, 1991). O segundo ponto é que os precursores das teorias neurológicas da histeria também sustentavam que as mulheres seriam as principais vítimas dessa afecção. Isso porque seu corpo, seus nervos e seu temperamento eram mais frágeis, o que as tornaria mais suscetíveis a adoecer. Assim, apesar de a etiologia neurológica da histeria tornar concebível a histeria masculina, os teóricos da concepção nervosa mantiveram-se ainda no território das mulheres.

Essa manutenção da histeria no território feminino foi reforçada ao longo dos séculos XVIII e XIX, fazendo parte da construção de uma determinada concepção da diferença entre os sexos articulada na modernidade, segundo a qual homens e mulheres seriam dotados de características físicas e morais diferentes e complementares (Laqueur, 2001). Os discursos médicos procuravam delinear minuciosamente as diferenças entre os sexos, 
supondo também patologias diferentes. Assim, por exemplo, a histeria seria feminina, e a hipocondria, masculina.

Essa formulação moderna da diferença entre os sexos pressupunha a diferença de essências, determinante dos papéis e funções sociais de homens e mulheres. Desenvolveuse na Europa no bojo da constituição do biopoder ${ }^{4}$, quando a mulher teve seu destino atrelado ao casamento e à maternidade. A partir da preocupação política com a produção da vida e a qualidade da população, a mulher e a maternidade tornaram-se objetos privilegiados de intervenção e controle. O que estava em pauta era a constituição de uma biopolítica concebida como a condição de possibilidade do manejo das fontes de vida para a produção da riqueza material e para a regulação dos laços sociais. A sexualidade tornou-se alvo primordial dessa biopolítica, pois pela reprodução individual e coletiva a produção de um corpo saudável e disciplinado estaria garantida (Foucault, 1994).

A família nuclear burguesa foi forjada nesse contexto e concebida como matriz da produção e reprodução dos indivíduos. Antes relegada a uma espécie de limbo, a mulher ganhou novo valor nessa nova ordem familiar e o poder de governar o espaço doméstico (Donzelot, 1980). Pensada como peça chave da estratégia de produção da vida e da saúde das crianças, a mãe tornou-se um dos pilares do biopoder.

A partir de então, configurou-se um processo maciço de medicalização do corpo feminino. Através de infinitas regras de higiene, buscava-se minucioso controle da vida e da sexualidade femininas, visando conter seus excessos e ardores, e adestrando as mulheres para a maternidade. Tal processo de medicalização deveria ser calcado em preceitos baseados nos cânones científicos da época. Assim, Georges Audiffrent (1823-1909), por exemplo, psiquiatra e neurologista francês que se inspirava nas teorias de Auguste Comte (17981857), propunha regras bastante delimitadas para a experiência sexual feminina: "As relações sexuais das mulheres devem estar restritas ao casamento, após 21 anos e ir até 35 anos, quando então o homem não deverá mais perturbá-la ... O homem também não deve perturbá-la no seu ofício de criar as crianças" (Audiffrent, 1874, p.368).

A maternidade tornou-se o destino politicamente desejável para as mulheres, e outras possibilidades subjetivas foram classificadas como "desviantes e antinaturais" (Nunes, 2000). Aquelas que não se adaptaram a esse projeto foram frequentemente descritas como histéricas. No século XIX, a histeria era ainda e sobretudo uma questão de mulheres (Catonné, 1992). A histérica era o protótipo da mulher nervosa, o negativo da mãe higiênica (Foucault, 1977b).

$\mathrm{Na}$ Europa da virada para o século XX, a questão da histeria ampliou-se, e a histeria masculina começou a ganhar espaço nos discursos médicos. Isso aponta para a configuração de um novo impasse. Elizabeth Roudinesco destaca a ocorrência do que considera uma verdadeira epidemia de sintomas histéricos entre 1880 e 1900. Médicos e moralistas viam, nas crises da sociedade industrial, sinais convulsivos de natureza feminina. Assim, as massas trabalhadoras eram chamadas de histéricas quando entravam em greve, enquanto multidões eram remetidas a seus "furores uterinos" quando ameaçavam a ordem estabelecida (Roudinesco, Plon, 1997).

A dificuldade de enquadrar a histeria em uma racionalidade anatomopatológica apresentava uma vantagem. Por ser categoria pouco delimitada e fluida, permitia sua 
utilização nas mais diferentes situações. Com isso os médicos puderam lançar mão à vontade do diagnóstico de histeria, patologizando comportamentos considerados desviantes e antissociais que não podiam ser facilmente atribuídos a outras doenças mentais.

Em todo esse percurso os discursos médicos e psiquiátricos tentaram exaustivamente apreender a natureza da histeria.

\section{Histeria, neurologia e psiquiatria}

Ao longo do século XVIII, a busca da etiologia da histeria engendrou, grosso modo, duas correntes distintas. Uma neurológica, cuja referência inicial foi William Cullen (1712$1790)^{5}$, que cunhou o termo neurose, com o qual pretendeu afirmar o lugar preponderante da neurologia. Ressaltou, assim, o campo das "doenças dos nervos", em que alocou a histeria.

Paralelamente, outra corrente se desenvolveu atribuindo à histeria fundamento psíquico. Assim, Joseph Raulin (1708-1784) ${ }^{6}$ descreveu a histeria como uma patologia da imaginação, não lhe atribuindo realidade orgânica. Em suas elaborações, reforçou a nascente teoria das paixões.

No século XIX, a partir da formulação da teoria da degenerescência, Bénédict-Augustin Morel (1809-1873) ${ }^{7}$ sugeriu que a histeria fosse uma forma de degeneração psíquica, concebida como uma desordem nos centros nervosos, hereditária e/ou adquirida, que estaria na base dos distúrbios mentais. O degenerado seria alguém que sucumbira a um processo civilizador deficiente, permanecendo em estádio evolutivo mais primitivo, constituindo ameaça ao desenvolvimento social.

Forjada no âmbito do projeto biopolítico de aperfeiçoamento da espécie, a categoria da degeneração articulava os registros do biológico e da civilização. Tornava concebível a intervenção nas patologias físicas e morais dos indivíduos, por meio de tratamentos médicos, visando a sua correção. Além disso, viabilizava uma ação junto às condições de produção das doenças, a hereditariedade e os males da civilização, por meio de projetos preventivos e de higiene pública e social.

Ao longo do século XIX, essa teoria ganhou força no pensamento psiquiátrico como explicação causal para as doenças mentais. Isso abriu as portas para a consolidação, nas últimas décadas, da tese segundo a qual a histeria seria hereditária e uma forma de degeneração psíquica.

Nesse momento, a disputa entre neurologistas e psiquiatras em torno da etiologia e da essência da histeria encontrou expressão maior no debate entre Jean Martin Charcot (1825-1893) $)^{8}$ e Hyppolyte Bernheim (1837-1919) ${ }^{9}$, entre La Salpêtrière e a Escola de Nancy (Trillait, 1991).

Charcot advogava que a histeria fosse uma alteração do sistema nervoso. Teria etiologia hereditária e seria produto de alguma degeneração, podendo ser disparada por traumas e choques mecânicos. Essas alterações nervosas possibilitariam a sugestionabilidade dos histéricos. Acreditava que, por meio da hipnose, a histeria latente se revelaria pela expressão sintomática. Seu poder como médico lhe permitia produzir esse efeito.

Bernheim contestava a hipótese neurológica e a ideia de que a hipnose revelaria uma doença latente. Acreditava que a histeria fosse produto direto da sugestão. Formulou, 
assim, uma hipótese psíquica da histeria. Ao substituir a hipnose pela sugestão, antecipou a separação entre neurologia e fato psíquico. Em sua opinião, a sugestão comprovava o caráter psicológico e relacional das afecções nervosas (Roudinesco, 1989).

Esse debate entre Charcot e Bernheim foi o ponto de partida do processo de desmembramento da histeria, que se desenvolveu a partir da virada para o século XX com Joseph Babinski (1857-1932) ${ }^{10}$ (Foucault, 1979; Roudinesco, 1989; Trillat, 1991).

No intuito de construir uma semiologia do sistema nervoso, Babinski procurou distinguir a histeria das afecções orgânicas. Sustentou sua dimensão psíquica, tirando-a do campo da neurologia. Contudo, considerava que seu quadro psíquico fosse dependente de predisposição mórbida hereditária. Em sua opinião, a histeria era um estado mórbido, determinado por predisposição hereditária, no qual o indivíduo seria capaz de autossugestão, podendo ser curado pela persuasão. Um estado mental que possibilitaria a produção de sintomas por sugestão e a cura pela persuasão. Propôs, então, que esses fenômenos mórbidos fossem denominados pitiatismo, que significa 'curável pela persuasão'. Sob o enquadramento do pitiatismo, a histeria foi concebida como uma 'simulação' e inserida no campo psiquiátrico.

Esse debate, no entanto, não abalou a assimilação da histeria ao binômio hereditariedade-degenerescência que se sustentou até o início do século XX, mesmo em meio aos defensores da etiologia psíquica da histeria. De maneira geral, considerava-se que a doença mental assentava-se em constituição já deficiente. Em 1911, Pierre Janet (1859-1947) ${ }^{11}$ ainda afirmava que as histéricas eram degeneradas hereditárias (Janet, 1911).

Ao apagar das luzes do século XIX, Sigmund Freud (1856-1939) ${ }^{12}$ propôs uma nova hipótese, deslocando definitivamente a histeria do campo somático para o psíquico. Além disso, se contrapôs explicitamente à associação histeria-hereditariedade-degeneração mental, que marcava o pensamento de seus contemporâneos (Freud, 1977). A radicalidade da hipótese freudiana, no entanto, não deu fim às controvérsias em torno da histeria. Ao contrário, colocou seus adeptos em campo oposto ao dos psiquiatras.

A psiquiatria alemã que se desenvolveu na aurora do século XX, a partir principalmente de Émil Kraepelin (1856-1926) ${ }^{13}$, sustentou os pressupostos organicistas das afecções mentais, indo na contramão da teoria freudiana. Kraepelin procurou reformular a psiquiatria observando como os sintomas se organizavam para formar doenças mentais específicas, caracterizando padrões ou síndromes. Rompeu assim com o método sintomático que balizava a psiquiatria oitocentista, inaugurando outro método clínico (Câmara, 2007). Nesse percurso, muito da sintomatologia anteriormente atribuída à histeria foi retomada no campo da demência precoce, da esquizofrenia, dos estados crepusculares, dos estados maníacos ou melancólicos, o que reforçou o processo de desmembramento da histeria (Trillait, 1991).

A histeria foi matéria de grande interesse da medicina brasileira, principalmente a partir das últimas décadas do século XIX, quando as histéricas foram descritas como verdadeiras ameaças à ordem social. Procurando minimizar tal ameaça, nossos médicos se debruçaram sobre as concepções psiquiátricas da histeria, reproduzindo os debates e as controvérsias de além-mar. 


\section{A histeria no Brasil}

A psiquiatria brasileira nasceu em meados do século XIX, no seio da constituição de uma medicina que incorporou a sociedade como novo objeto e se impôs como instância de controle social dos indivíduos e das populações. Nasceu no bojo de um projeto de medicalização da sociedade que se voltou para a prevenção das doenças, dos desregramentos morais e da desagregação social (Machado et al., 1978).

Nesse contexto, a mulher burguesa foi convocada a exercer novo papel, o de esposa e mãe (Freire Costa, 1979). Médicos e moralistas formularam projetos de intervenção sobre o corpo e a alma femininas. Pretendiam regular desejos e formas de vida, adestrando as mulheres para as funções que lhes estavam sendo determinadas - aquelas ligadas aos cuidados das crianças e à formação de uma população saudável. A partir da segunda metade do século XIX, é cada vez maior o número de teses e artigos médicos voltados para a higiene da primeira infância e da maternidade. Esses textos advogavam a importância da aquisição dos preceitos de higiene física e moral que pregavam e que consideravam ser a bússola a guiar a relação materno-infantil: "A higiene ajudará a criança que não pode e a mãe que não sabe. É na infância que se estabelece a base de uma boa ou má saúde. Os livros de higiene da infância são considerados em toda parte como uma grande necessidade demonstrada" (Silva, 1882, p.10). As que se desviavam desse projeto foram descritas como perversas, loucas e, principalmente, histéricas (Nunes, 1991).

Os primeiros trabalhos e teses brasileiras sobre alienação mental baseavam-se no trabalho de Esquirol (1772-1840) ${ }^{14}$ e apoiavam-se em autores estrangeiros, retomando seus conflitos teóricos sobre a natureza da doença mental (Machado et al., 1978). Os estudos sobre a histeria importaram essas mesmas referências, acompanhando tanto o debate travado em torno da natureza da doença quanto sua associação direta com o sexo feminino. A histeria, nos discursos médicos e psiquiátricos brasileiros da segunda metade do século XIX, foi desenhada no feminino. As histéricas eram percebidas como mulheres que não se adaptavam ao papel que lhes era reservado na família e na sociedade. Temia-se que uma imaginação "desregrada e superexcitada" as tornasse verdadeiras 'Messalinas', sendo levadas ao adultério e à prostituição (Paula, 1889; Fernandes Figueira, 1886).

Nas duas últimas décadas do século XIX, com a abolição da escravidão e a proclamação da República, essa perspectiva se intensificou e ampliou. Os discursos médicos voltaram-se cada vez mais para uma perspectiva de higiene moral, propondo o adestramento dos sentimentos e das paixões. Nesse contexto, a teoria da degeneração ganhou destaque. A crença no risco de que o indivíduo sucumbisse a seus aspectos degenerativos e/ou os transmitisse à descendência caucionou um aprofundamento das intervenções médica e psiquiátrica sobre a população (Nunes, 1991).

Os trabalhos sobre histeria defendiam majoritariamente sua inclusão no quadro das degenerações (Paula, 1889). A questão feminina permanecia no centro das preocupações, e os discursos médicos sustentavam a maior incidência de histeria em mulheres. Argumentava-se que sua estrutura física e mental as predispunha à degeneração e à histeria (Castro, 1894). O saber produzido nesses discursos se materializava no cotidiano das práticas psiquiátricas, como atesta o fato de que o diagnóstico de histeria foi prevalente entre as 
mulheres internadas no Hospício Nacional dos Alienados até a década de 1920 (Facchinetti, Ribeiro, Muñoz, 2008).

No entanto, apesar da primazia dada ao sexo feminino, a relevância atribuída à teoria da degeneração, na virada para o século XX, deu força à tese de que a histeria afetaria também o sexo masculino (Engel, 2008). Considerou-se que a histeria se poderia apresentar em todos aqueles dotados de constituição mais frágil ou que tivessem sido excessivamente expostos às mazelas da civilização, fossem eles homens ou mulheres.

Um fator fundamental para a expansão da teoria da degeneração no Brasil está ligado à questão racial. Entre 1870 e 1930, esse era um tema de reflexão e debates em diferentes áreas do pensamento brasileiro. Depois da abolição, a percepção de negros e mestiços como pouco evoluídos e inferiores se acentuou, e a questão da raça passou a ser 'científica', vista pelo ângulo da degeneração psíquica (Oda, Dalgalarrondo, 2003). Os médicos que atribuíam a essa população constituição deficiente e desregrada se preocupavam com os efeitos nefastos dessa degenerescência sobre o futuro da nação.

Outro fator importante foi que, com a desagregação do sistema escravocrata, cidades como o Rio de Janeiro viram crescer uma massa populacional formada por negros libertos, mestiços, brancos pobres e imigrantes, que deu origem a um proletariado nascente e uma população marginal urbana (Albuquerque, 1981). Percebida como desregrada, essa população era considerada ameaça à ordem social, e os discursos médicos 'patologizavam' seus hábitos, moralidade, religiosidade e reivindicações sociais (Engel, 1998). Esses indivíduos forneceram o maior contingente de internos ao Hospital Nacional dos Alienados, fortalecendo a imagem negativa e o temor das elites em relação a esses setores da população (Facchinetti, Ribeiro, Muñoz, 2008).

A teoria da degeneração possibilitou que, ao longo da Primeira República, os projetos voltados para a higiene e o controle do corpo social fossem dirigidos cada vez mais para a massa trabalhadora e para os setores populacionais marginalizados. São frequentes, nesse período, trabalhos sobre higiene das fábricas, a importância da educação popular e a necessidade de organizar as famílias operárias (Nunes, 1988).

Nas primeiras décadas do século XX, o paradigma que associou as diferentes formas de alienação mental a deficiências nervosas e estilos de vida inadequados estava definitivamente estabelecido. O binômio hereditariedade-degenerescência ocupou, então, lugar quase hegemônico, nos discursos psiquiátricos, como fator causal das afecções mentais.

A entrada em cena da psicanálise, saber que se originou do estudo e do tratamento da histeria, não abalou essas convicções. As teorias psicanalíticas tiveram dificuldade em penetrar o universo de cunho tão organicista da psiquiatria brasileira (Engel, 1999). No entanto, nossos psiquiatras conheciam as teses freudianas. Na segunda década do século XX, expoentes da psiquiatria brasileira como Henrique Roxo (1877-1969) ${ }^{15} \mathrm{e}$ Franco da Rocha (1864-1933) ${ }^{16}$ já haviam incorporado concepções formuladas no âmbito da psicanálise (Engel, 2008, Nunes 1998); resistiam, porém, a subscrevê-las. Em nome da crítica ao que consideravam pansexualismo freudiano, defendiam a tese fisicalista, segundo a qual a degeneração e a hereditariedade seriam o solo da histeria. A psicanálise só lhes parecia interessante como método de investigação por permitir desvendar uma verdade que acreditavam oculta sob o véu da dissimulação histérica (Rocha, 1920; Roxo, 1919). 
Essa concepção organicista vai ser reforçada com a adesão de nossos alienistas à psiquiatria alemã, representada primordialmente por Kraepelin. Juliano Moreira (1873-1933) ${ }^{17}$ foi um de seus grandes adeptos e se dedicou a implementar aquelas concepções no Brasil (Venâncio, 2004).

Juliano Moreira introduziu a psiquiatria científica de Kraepelin e com ela a proposta de novo modelo assistencial, de perspectiva abrangente, não restrita ao espaço asilar (Portocarrero, 2005), um modelo condizente com o projeto reformador e preventivista que caracterizou a medicina brasileira da Primeira República. Essa medicina se acreditava capaz de dirigir o processo de modernização e sanitarização do país (Oda, Dalgalarrondo, 2000). Foi nesse contexto que Antônio Austregésilo escreveu seu artigo "Histeria e síndrome histeroide".

\section{Antônio Austregésilo e o desmembramento da histeria}

Antônio Austregésilo Rodrigues Lima nasceu em 1876, em Recife, e faleceu em 1960, no Rio de Janeiro. Considerado pioneiro da neurologia brasileira, foi designado em 1912 para a recém-fundada cátedra de Neurologia da Faculdade de Medicina do Rio de Janeiro. Seus trabalhos nesse campo são considerados de grande importância para o desenvolvimento dessa especialidade no Brasil (Teive et al., 1999).

Interessou-se pela neurologia e pela psiquiatria ainda na Faculdade de Medicina, tendo concluído seu curso em 1899 com a tese Estudo clínico do delírio. No governo Rodrigues Alves, integrou a equipe de Juliano Moreira, que assumiu a Diretoria da Assistência a Alienados. Foi nomeado médico do Hospício Nacional dos Alienados em 1904 e em 1905 tornou-se responsável pela ala masculina daquele hospital. Deixou o cargo em 1910, ao ser nomeado professor da Faculdade de Medicina do Rio de Janeiro. ${ }^{18}$

Desenvolveu intensa produção científica no campo da psiquiatria e foi importante colaborador dos Arquivos Brasileiros de Medicina e dos Arquivos Brasileiros de Neurologia e Psiquiatria. Escritor e ensaísta, foi eleito em 1914 para a Academia Brasileira de Letras (Teive et al., 1999). Estudioso dos problemas relativos à saúde mental e à psicologia, foi um dos primeiros alienistas brasileiros a introduzir as teorias psicanalíticas no Brasil (Nunes, 1988).

Situada na encruzilhada da neurologia com a psiquiatria, a histeria foi para ele tema de grande interesse, sobre o qual escreveu artigos importantes, que inspiraram a produção psiquiátrica brasileira das primeiras décadas do século XX.

Em paralelo, interessou-se vivamente pela questão feminina, trilhando a contramão da descrição corrente do feminino naquela velha República que "bordejava a insanidade mental" (Bocayuva, 2007, p.157). Escreveu, entre outros trabalhos sobre o tema, O perfil da mulher brasileira, cuja primeira edição é de 1922 e em que faz minucioso estudo sobre a mulher brasileira, louvando suas inúmeras qualidades afetivas e maternais e propondo adestramento e aperfeiçoamento de suas deficiências que, entendia, seriam fruto de educação insuficiente ou inadequada (Austregésilo, 1946).

Afinado com as propostas de Juliano Moreira, identificava-se com a perspectiva de medicina voltada para a higiene física e moral do povo brasileiro (Moreira, 1906). Preocupavase com a prevenção dos males causados tanto pelas diáteses hereditárias quanto pelos 
problemas resultantes do progresso e da industrialização. A mulher foi objeto de seu interesse por ser peça fundamental no aperfeiçoamento do homem brasileiro.

É curioso notar, entretanto, que o interesse de Austregésilo pelo sexo feminino não resultou em reflexão maior quanto à associação entre histeria e feminilidade. Em seus artigos sobre histeria, a referência que faz à questão é apenas para observar que, devido à imprecisão dessa categoria, ela tornou-se "diagnóstico de facilidade, sobretudo em se tratando do sexo feminino" (Austregésilo, 1908, p.52). Isso marca relevante diferença em relação a muitos de seus contemporâneos. Henrique Roxo, por exemplo, comenta, em seu artigo "Histeria", que se vai ocupar do "estado mental das histéricas", no feminino, reforçando assim essa associação e a permanência da imagem da mulher histérica (Roxo, 1905).

Ao abordar a questão da histeria, Austregésilo tinha como meta principal desvelar sua natureza e circunscrevê-la a um determinado quadro nosográfico. Para isso tomou como referência o trabalho de Babinski e sua concepção de pitiatismo. Defendeu, então, a existência de uma histeria verdadeira - a síndrome histérica ou pitiática - e uma pseudohisteria - a síndrome histeroide ou falsa histeria. Com essa separação, pretendeu desbastar o campo da histeria, mostrando que muitos casos diagnosticados como tal correspondiam, na verdade, a outras afecções psíquicas ou mesmo físicas.

Criticava enfaticamente a superabundância de diagnósticos de histeria na clínica civil e nos hospitais de alienados. Sua hipótese era que "os casos de afecções nervosas difíceis, insólitos, sobretudo em mulheres, tomavam o rótulo de histeria" (Austregésilo, 1908). Argumentava que, diante da profusão de hipóteses sobre a histeria e da facilidade com que os médicos lançavam mão desse diagnóstico, uma reação era necessária, o que foi feito por Babinski ao propor que os diagnósticos de histeria fossem circunscritos aos parâmetros fixados pelo neurologista francês, segundo o qual a histeria seria síndrome produzida por autossugestão e curável pela persuasão.

Em "Novas concepções sobre a histeria", seu primeiro trabalho sobre o assunto, publicado em 1908, Austregésilo faz um recenseamento das teorias que estavam em voga desde o final do século XIX, mostrando seus limites e valorizando os pontos que corroboravam a tese de que a sintomatologia histérica era um fenômeno psíquico produzido por sugestão. Assim, se alinhou às correntes que colocavam a histeria no campo da psiquiatria e não no da neurologia. "A histeria ou pitiatismo mostra-se como uma doença mental. É a imaginação em terreno autossugestionável que faz com que o histérico apresente a série de perturbações primitivas e secundárias" (Austregésilo, 1908, p.54).

Contudo, suas elaborações atestam sua própria dificuldade em situar essa neurose. Por um lado, afirmava que a histeria era produto da sugestão e, portanto, uma afecção mental. Por outro, admitia tratar-se de psiconeurose que se desenvolvia a partir de uma grande diátese: o nervosismo. A categoria de nervosismo tinha, no entanto, sabor organicista, já que remetia ao sistema nervoso e a suas fibras (Foucault, 1978); era, porém, bastante útil por seu caráter totalizante. Abarcava ao mesmo tempo uma dimensão fisicalista e uma dimensão moral, pois tinha raízes nos supostos males da civilização (Duarte, 1988).

Austregésilo considerava o nervosismo uma diátese caracterizada pelo máximo de reação nervosa ao mínimo de excitação. Uma diátese do "dinamismo nervoso anormal". De acordo com sua hipótese, desse terreno comum brotavam os fenômenos histéricos, 
neurastênicos, hipocondríacos e obssessivos, ou seja, as diferentes psiconeuroses. Portanto, ao colocar o nervosismo na base da histeria, sustentou sua dimensão mental, mas ao mesmo tempo deixou-a enraizada no registro da fisicalidade.

A resistência em tratar a histeria como fato puramente psíquico foi explicitada mais tarde, quando reconheceu a impossibilidade de explicar a histeria exclusivamente a partir de uma única vertente, fosse psicológica ou orgânica (Austregésilo, 1932). Essa marca fisicalista será determinante da forma como ele incorporaria, posteriormente, os preceitos psicanalíticos em seu pensamento (Austregésilo, 1926).

Outro aspecto interessante é que a categoria nervosismo, ao associar fisicalidade a males da civilização, apontava para a existência de predisposições que se poderiam manifestar a partir de condições de vida impróprias e que não fossem pautadas por preceitos adequados de higiene. Reafirmava, portanto, o arcabouço da teoria da degeneração.

Nessas idas e vindas, três pontos se destacam e demonstram os aspectos centrais quanto aos problemas colocados pela histeria para o projeto de higiene social que se instalava. $\mathrm{O}$ primeiro é que, por trás da constatação do autor acerca da existência de excesso de diagnósticos de histeria, fica evidenciado o quanto a necessidade de enquadrar a histeria em um quadro nosográfico era, no início do século XX, uma questão importante para a psiquiatria brasileira. Isso porque, no projeto de constituição de uma psiquiatria científica, delimitar uma doença merecedora de tanta atenção era tarefa fundamental. O segundo é que, embora Austregésilo não explicitasse sua adesão à associação da histeria à degeneração psíquica, isso não quer dizer que esta categoria estivesse ausente em suas teses. Tanto a concepção de pitiatismo de Babinski quanto a psiquiatria científica de Kraepelin pressupunham, em seu arcabouço teórico, a hipótese da degeneração - o que explica a presença dessa categoria em alguns de seus relatos clínicos e em prontuários de pacientes que atendeu no Hospício Nacional de Alienados. ${ }^{19} \mathrm{O}$ terceiro é que, ao observar que tal diagnóstico era atribuído com muita facilidade às mulheres, isso nos permite confirmar o quanto a histeria era, naquele momento, um problema feminino por excelência. Além disso, esse excesso de diagnósticos aponta ainda para a guerra surda travada nos asilos com essas mulheres. Mulheres que tinham em comum, segundo os laudos e perícias médicas, o fato de não cumprir adequadamente seus papéis de esposa e mãe (Engel, 1997).

Em "Histeria e síndrome histeroide", publicado em 1909, Austregésilo apresenta sete observações clínicas que ilustram esses três pontos.

O primeiro aspecto que fica ressaltado nesses relatos é o esforço que ele realiza para comprovar sua hipótese, delimitando a síndrome histeroide em cada caso. Todos os casos são de pacientes que foram internados no Hospício Nacional de Alienados com diagnóstico de histeria. Em todos procura demonstrar o equívoco em que os médicos incorriam, considerando que a evolução dos casos evidenciou que os pacientes sofriam de outras afecções, sobre as quais se desenvolveram as síndromes histeroides.

Apoiando-se no trabalho de Kraepelin que, ao abordar o campo da paranoia, distinguiua da demência paranoide, Austregésilo procurava justificar suas hipóteses. Argumentava que, até dez anos antes, tudo era paranoia nos manicômios brasileiros e que isso só se modificou com o trabalho de Juliano Moreira e Afrânio Peixoto (1876-1947) ${ }^{20}$, que introduziram a distinção kraepeliniana, desbastando esse campo. Defendia o mesmo em 
relação à histeria. Procurou, então, levar a cabo essa tarefa, distinguindo a verdadeira histeria das síndromes histeroides que se apresentavam em outros quadros clínicos. Assim, separando o joio do trigo, pretendeu sustentar a psiquiatria científica que então se instalava.

Para Austregésilo, ao lado dos histéricos perfeitos, - natos ou adquiridos, mas quase sempre natos -, há falsos histéricos, simples nervosos, instáveis, degenerados simples, sem rótulo, psicopatas, ciclotímicos, maníaco-depressivos elementares que nada têm de histeria. Assim como há verdadeiros e falsos neurastênicos, há verdadeiros e falsos histéricos. E assim como Pibram chama de reumatoides os falsos reumatismos, Kraepelin, Moreira e Peixoto denominam paranoides os ouropéis da paranoia, e seria preciso admitir o verdadeiro histérico e o falsificado, o histeroide síndromático (Austregésilo, 1909, p.76).

Os casos relatados em seu artigo ilustram bem sua tese: dois deles tiveram o diagnóstico alterado para demência precoce, dois para loucura maníaco-depressiva, um para intoxicação alcoólica, um para tumor cerebral, e o último para debilidade mental.

O segundo ponto que podemos apreender desses relatos clínicos é a marca de sua filiação aos pressupostos da teoria da degeneração. Pertencendo a uma geração de alienistas que buscava um projeto de nação no qual a questão do aperfeiçoamento do povo brasileiro era uma das bandeiras, Austregésilo abraçou com afinco essa causa.

Ao longo da Primeira República, esse projeto voltou-se cada vez mais para as classes trabalhadoras empobrecidas e para os setores populacionais mais marginalizados. Ambos começavam a ganhar importância política e reivindicar melhores condições sociais. Houve forte movimento operário e organizaram-se associações civis de negros e mulheres.

Nesse contexto, o tal desregramento dos hábitos e das paixões do povo alarmava bastante os médicos. Privilegiando um projeto de intervenção junto a negros e mestiços, considerados potencialmente degenerados, seus discursos adquirem tom claramente racista. A alegada falta de educação, moralidade e disciplina dessa população justificava programas voltados para o controle de seus estigmas degenerativos. A expansão dessa política desaguou na fundação da Liga Brasileira de Higiene Mental que, em 1926, passou a defender um projeto claramente eugênico (Freire Costa, 1979).

Austregésilo não se alinhava explicitamente aos discursos que tratavam negros e mestiços como degenerados inferiores. Em seus escritos, seja na produção científica ou nos ensaios mais voltados para o público em geral, a preocupação com os preceitos de higiene física e moral visando à melhoria da qualidade da população é certamente a tônica. No entanto, não se observa menção clara à questão da raça, como aparece em boa parte de seus contemporâneos (Freire Costa, 1979). Apesar disso, as descrições dos pacientes apresentados em "Histeria e síndrome histeroide" apontam uma contradição. É apenas nos exames dos pacientes negros ou pardos que aparecem descrições detalhadas de traços e características físicas, com a explicitação da presença dos chamados estigmas degenerativos. Nos relatos dos pacientes de cor branca, a palavra 'degeneração' está ausente, e o exame das características físicas, quando presente, é pouco detalhado. Isso demonstra sua preocupação com os aspectos degenerativos atribuídos a negros e mestiços, e com os possíveis riscos que eles representavam ao projeto de constituição de uma raça saudável, livre de taras e vícios. 
O terceiro aspecto relevante diz respeito à associação entre sexo feminino e histeria, que Austregésilo parecia não querer sustentar. Uma hipótese para essa postura é a de que desmontar essa associação era passo importante na construção de um diagnóstico científico para a doença. As controvérsias em torno da etiologia da histeria e de sua incidência em homens revelavam uma babel teórica na qual neurologistas, psiquiatras e especialistas em doenças femininas se digladiavam. Talvez por isso, apesar de seu interesse tanto pela histeria quanto pela psicologia feminina, Austregésilo evitasse problematizar tal questão em suas considerações teóricas.

Outra hipótese possível é a de que desconstruir a imagem negativa da mulher, frequentemente assimilada à imagem também negativa da histeria, era, por sua vez, passo importante para o projeto de higiene social do qual era defensor. Ao contrário de grande parte do pensamento psiquiátrico brasileiro da época (Nunes, 1991), Austregésilo tinha imagem positiva do sexo feminino. Assim, tornava possível justificar a delegação dos cuidados infantis às mães (Austregésilo, 1946). Em seu artigo, relata apenas três casos de pacientes do sexo feminino. Em nenhum faz uma descrição desabonadora de sua moral, o que era comum em se tratando de mulheres.

Essas três pacientes tiveram o diagnóstico de histeria questionado. Duas receberam o de maníaco-depressivas, e a terceira, de tumor cerebral. Os diagnósticos apontam para um dado interessante, que parece revelar o sucesso obtido pelo desmembramento da histeria com o consequente esvaziamento da relação entre histeria e feminino.

Até a década de 1920, a maior parte dos diagnósticos recebidos pelas mulheres no Hospício Nacional dos Alienados era de histeria. Além disso, segundo Henrique Roxo, a histeria era a maior causa de reincidências no Hospital, entre as mulheres (Facchinetti, Ribeiro, Muñoz, 2008). A partir de 1920, contudo, tornaram-se mais raros, chegando a menos de $2 \%$ na década de 1930 . Em contrapartida, a maior parte das internas passou a receber o diagnóstico de maníaco-depressiva, em contexto no qual essa forma de loucura foi associada aos períodos menstruais (Facchinetti, Ribeiro, Muñoz, 2008). Afinal, se a histeria foi aos poucos sendo esvaziada de sentido, era necessário encontrar novos diagnósticos que apreendessem a experiência feminina de loucura e justificassem alguma intervenção sobre aquelas percebidas como incapazes de cumprir adequadamente seu papel social.

A associação da loucura maníaco-depressiva com os períodos menstruais caiu então como uma luva, porque reeditava, em outras bases, a velha relação dos desvarios femininos com os desregramentos dos ciclos vitais. No lugar do útero entraram em cena os hormônios ovarianos, que começavam a ganhar lugar de destaque nas pesquisas médicas (Rohden, 2008). Os ciclos vitais reprodutivos femininos passaram a representar uma ameaça. Não por acaso encontramos, nos discursos médicos da Primeira República, uma intensificação da preocupação com os cuidados a serem ministrados às mulheres nos diferentes períodos de seu ciclo hormonal. Foi também nesse momento que o diagnóstico de loucura puerperal ganhou destaque nos discursos psiquiátricos (Nunes, 1982).

A reinterpretação da loucura feminina em torno do paradigma hormonal foi fundamental para o desmembramento da histeria no campo da psiquiatria. Tal desmembramento, assim como a desconstrução da associação entre histeria e feminino, teve 
consequências importantes para a psiquiatria das primeiras décadas do século XX. Reduzida à dimensão psíquica do pitiatismo e assimilada à ideia de simulação, a histeria foi deslocada do campo da medicina, deixando de ser ameaça à racionalidade anatomopatológica, na qual não se enquadrava. No entanto, esse esvaziamento não implicou afrouxamento dos projetos de intervenção junto à população feminina, pois outra forma de loucura lhe foi associada.

Se no caso da histeria as querelas em torno do acometimento da população masculina dificultavam sua assimilação exclusiva ao sexo feminino, na loucura maníaco-depressiva esse problema deixava de existir. Recuperando a velha ligação fundamental com o corpo da mulher, e através da associação da doença aos hormônios femininos, ressaltava-se a ideia de que a possibilidade de adoecer estava inscrita nesse próprio corpo, o que justificava o projeto médico de intervenção ao longo de toda a sua vida reprodutiva.

Formado no bojo de um projeto médico que incorporou a sociedade como seu objeto de intervenção, Antônio Austregésilo foi figura de proa dessa causa. Seus escritos sobre histeria dão testemunho de alguns problemas que estavam colocados para a medicina mental daquele período, uma medicina que disputava lugar entre as instâncias de controle da vida social, já que pretendia deter, sobre a doença e a saúde, um saber calcado em critérios científicos - saber que, em nome da preservação da saúde e do aperfeiçoamento da população, justificou atuação direta sobre o espaço social, os indivíduos e as suas formas de vida.

\section{NOTAS}

${ }^{1}$ Lange, médico francês, autor de Traité des vapeurs (1689).

2 Thomas Willis, médico, filósofo, anatomista e fisiologista inglês.

${ }^{3}$ Thomas Sydenham, médico inglês, considerado o Hipócrates britânico, por ter restaurado os princípios hipocráticos da medicina.

${ }^{4}$ Segundo Foucault (1977b), o biopoder se constituiu como modalidade de poder voltada principalmente para a produção da vida e regulação da população. Nesse contexto, os processos biológicos, do nascimento à morte, tornaram-se alvos de biopolítica que pressupunha o engendramento e controle contínuo da vida.

${ }^{5}$ William Cullen, médico escocês que sugeriu ser a neurose resultado de distúrbio do sistema nervoso, mesmo sem apresentar lesão perceptível.

${ }^{6}$ Joseph Raulin, médico francês com diversos trabalhos em ginecologia e obstetrícia; publicou, em 1758, o Traité des affections vaporeuses du sexe.

7 Bénédict-Augustin Morel publicou o Traité des dégénerecences physiques, intelectuelles et morales de l'espèce humaine em 1857. Definiu a degenerescência como um desvio do homem perfeito, hereditário e responsável pelas anormalidades físicas e morais.

${ }^{8}$ Jean Martin Charcot, médico francês, foi nomeado, em 1882, professor da clínica de doenças nervosas de La Salpêtrière; montou e descreveu o quadro da 'grande histeria', procurando enquadrá-la ao método anatomoclínico.

${ }^{9}$ Hyppolyte Bernheim, médico francês, clínico geral, foi nomeado professor de clínica médica em Nancy em 1878.

${ }^{10}$ Joseph Jules François Félix Babinski, neurologista francês conhecido por descobrir o sinal que levou seu nome, sinal de Babinski; foi discípulo de Charcot. Trabalhou no Hospital de la Pitié, no qual se dedicou à atividade clínica.

11 Pierre Marie Félix Janet, filósofo, psicólogo e neurologista, foi figura de proa da psicologia clínica francesa do século XIX. Publicou L'état mental des hysteriques, em 1892. 
${ }^{12}$ Sigmund Freud, médico e neurologista vienense, estudou com Charcot e Bernheim e escreveu Estudos sobre a histeria entre 1893 e 1895 . Foi o criador da psicanálise.

${ }^{13}$ Emil Kraepelin, psiquiatra alemão, é considerado o criador da moderna psiquiatria. Considerava que as doenças mentais eram causadas por alterações biológicas e fisiológicas. Elaborou uma descrição geral e uma classificação das doenças mentais. Publicou, em 1883, o Compendium der Psychiatrie.

${ }^{14}$ Jean Éttienne-Dominique Esquirol, alienista francês, discípulo de Pinel no Hospital La Salpêtrière, desenvolveu sistematização nosográfica da loucura fundamentada na observação clínica sistemática e na delimitação de categorias psicopatológicas estáveis.

${ }^{15}$ Henrique Britto de Belford Roxo formou-se pela Faculdade de Medicina do Rio de Janeiro, com a tese de doutoramento Duração dos atos psíquicos elementares nos alienados, em 1901. Foi catedrático de clínica psiquiátrica em 1921, diretor do Instituto de Neuropatologia e membro de inúmeras instituições médicas, nacionais e estrangeiras. Realizou diversos estudos na área de neuropsiquiatria e neurologia. Foi membro titular da Academia Nacional de Medicina a partir de 1922.

${ }^{16}$ Francisco Franco da Rocha graduou-se na Faculdade de Medicina do Rio de Janeiro e fez sua formação de alienista no Hospício Nacional. Foi fundador, em 1898, do Asilo de Alienados do Juqueri, que em 1928 passou a se denominar Hospital e Colônias de Juqueri e, mais tarde, Hospital Psiquiátrico do Juqueri, localizado no atual município de Franco da Rocha.

${ }^{17}$ Juliano Moreira graduou-se pela Faculdade de Medicina da Bahia em 1891, com a tese Sífilis maligna precoce. Em 1903 assumiu a direção do Hospício Nacional dos Alienados, que manteve até 1930. Tornouse diretor da Assistência Nacional a Alienados em 1911. Com Afrânio Peixoto, fundou os Arquivos Brasileiros de Medicina e a Sociedade Brasileira de Psiquiatria, Neurologia e Ciências Afins.

${ }^{18}$ A esse respeito, ver Brasil, 1904, 1905, 1910.

${ }^{19}$ A esse respeito ver prontuários do Hospício Nacional de Alienados (HNA), no acervo do Instituto Municipal de Assistência a Saúde Nise da Silveira (Imas-NS).

${ }^{20}$ Júlio Afrânio Peixoto formou-se em medicina em Salvador, em 1897, com a tese Epilepsia e crime. Integrou a equipe de Juliano Moreira no Hospício Nacional dos Alienados e foi inspetor de Saúde Pública. Foi designado professor da cadeira de Medicina Legal da Faculdade de Medicina do Rio de Janeiro em 1907.

\section{REFERÊNCIAS}

ALBUQUERQUE, Manoel Maurício.

Pequena história da formação social brasileira. Rio de Janeiro: Graal. 1981.

AUDIFFRENT, M. G.

Des maladies du cerveau et de l'innervation d'aprés August Comte. Paris: Ernest Leroux. 1874.

AUSTREGÉSIL0, Antônio.

O perfil da mulher brasileira. Rio de Janeiro: Guanabara. 1946.

AUSTREGÉSIL0, Antônio.

O conceito clínico de psiconeuroses. Rio de Janeiro: Guanabara Koogan. 1932.

AUSTREGÉSIL0, Antônio.

As forças curativas do espírito. Rio de Janeiro: Francisco Alves. 1926

AUSTREGÉSIL0, Antônio.

Hysteria e syndromo hysteroide. Archivos Brasileiros de Psychiatria, Neurologia e Medicina Legal, Rio de Janeiro, v.5, n.1-2, p.59-77. 1909.

AUSTREGÉSIL0, Antônio.

Novas concepções sobre histeria. Archivos
Brasileiros de Psychiatria, Neurologia e Medicina Legal, Rio de Janeiro, v.4, n.1-2, p.52-66. 1908.

\section{BIRMAN, Joel.}

Gramáticas do erotismo. Rio de Janeiro: Civilização Brasileira. 2001.

BOCAYUVA, Helena.

Sexualidade e gênero no imaginário brasileiro, metáforas do biopoder. Rio de Janeiro: Revan. 2007.

BRASIL.

Ministério da Justiça e Negócios Interiores. Ministro (Esmeraldino Olympio de Torres Bandeira). Relatorio dos annos de 1909 e 1910 apresentado ao presidente dos Estados Unidos do Brazil... em abril de 1910. Rio de Janeiro: Imprensa Nacional. 1910.

BRASIL.

Ministério da Justiça e Negócios Interiores. Relatorio apresentado ao Exmo. Sr. Dr. J.J. Seabra, Ministro da Justiça e Negocios Interiores, pelo Dr. Afranio Peixoto, diretor interino do Hospicio Nacional de Alienados (1904-1905). Rio de Janeiro: Imprensa Nacional. 1905. 
BRASIL.

Ministério da Justiça e Negócios Interiores. Ministro (José Joaquim Seabra). Relatorio dos annos de 1903 e 1904 apresentado ao presidente dos Estados Unidos do Brazil... em março de 1904. Rio de Janeiro: Imprensa Nacional. 1904.

CÂMARA, Fernando Portela.

A construção do diagnóstico psiquiátrico.

Revista Latinoamericana de Psicopatologia

Fundamental, São Paulo, v.10, n.4, p.677-684. 2007.

CASTRO, Tito Lívio.

A mulher e a sociogenia. Rio de Janeiro: Guanabara. 1894.

CATONNÉ, Jean-Phillipe.

Femmes et hysterie au XIXe siècle. Synapse, Paris, n.88, p.33-43. 1992.

DONZELOT, Jacques.

A polícia das famílias. Rio de Janeiro: Graal. 1980.

DUARTE, Luiz Fernando Dias.

Da vida nervosa nas classes trabalhadoras urbanas. Rio de Janeiro: Jorge Zahar. 1988.

ENGEL, Magali Gouveia.

Sexualidades interditadas: loucura e gênero masculino. História, Ciências, Saúde -

Manguinhos, Rio de Janeiro, v.15, supl., p.173-190. 2008.

ENGEL, Magali Gouveia.

As fronteiras da 'anormalidade': psiquiatria e controle social. História, Ciências, Saúde Manguinhos, Rio de Janeiro, v.5, n.3. p.547-563. 1999.

ENGEL, Magali Gouveia.

Psiquiatria e feminilidade. In: Del Priore, Mary (Org.). História das mulheres no Brasil. São Paulo: Contexto; Unesp. 1997.

FACCHINETTI, Cristiana; RIBEIRO, Andréa; MUÑOZ, Pedro F. de.

As insanas do Hospício Nacional de Alienados (1900-1939). História, Ciências, Saúde Manguinhos, Rio de Janeiro, v.15, supl., p.231-242. 2008.

FERNANDES FIGUEIRA, Antônio.

Condições patológicas e modalidades clínicas da histeria. Tese apresentada à Faculdade de Medicina do Rio de Janeiro, Rio de Janeiro. 1886.

FOUCAULT, Michel.

Les mailles du poivoir. In: Foucault, Michel. Dits et écrits. v.4. Paris: Gallimard. p.182-212. 1994.
FOUCAULT, Michel.

A casa dos loucos. In: Foucault, Michel. Microfísica do poder. Rio de Janeiro: Graal. p.113-128. 1979.

FOUCAULT, Michel.

História da loucura. São Paulo: Perspectiva. 1978.

FOUCAULT, Michel.

O nascimento da clínica. Rio de Janeiro: Forense Universitária. 1977a.

FOUCAULT, Michel.

História da sexualidade, v.1: A vontade de saber. Rio de Janeiro: Graal. 1977b.

FREIRE COSTA, Jurandir.

Ordem médica e norma familiar. Rio de Janeiro: Graal. 1979.

FREIRE COSTA, Jurandir.

História da psiquiatria no Brasil. Rio de Janeiro: Documentário. 1976.

FREUD, Sigmund.

A etiologia da histeria. In: Freud, Sigmund.

Obras completas. Rio de Janeiro: Imago.

1.ed.,1896. 1977.

JANET, Pierre.

L'état mental des hystériques. Paris: Félix Alcan. 1911.

LAQUEUR, Thomas.

Inventando o sexo. Rio de Janeiro: Relume Dumará. 2001.

MACHADO, Roberto et al.

Danação da norma: medicina social e constituição da psiquiatria no Brasil. Rio de Janeiro: Graal. 1978.

MOREIRA, Juliano.

Ligeiras notas a propósito da assistência familiar. Archivos Brasileiros de Pychiatria, Neurologia e Sciencias Affins, Rio de Janeiro. 1906.

NUNES, Silvia Alexim.

O corpo do diabo entre a cruz e a caldeirinha: um estudo sobre a mulher, o masoquismo e a feminilidade. Rio de Janeiro: Civilização Brasileira. 2000.

NUNES, Silvia Alexim.

A medicina social e a questão feminina. Physis: Revista de Saúde Coletiva, Rio de Janeiro, v.1, n.1, p.49-76. 1991.

NUNES, Silvia Alexim.

Da medicina social à psicanálise. In: Birman, Joel (Org.). Percursos na história da psicanálise. Rio de Janeiro: Taurus. 1988. 
NUNES, Silvia Alexim.

Medicina social e regulação do corpo feminino. 1983. Tese (Doutorado) - Instituto de Medicina Social, Universidade do Estado do Rio de Janeiro, Rio de Janeiro. 1983.

ODA, Ana Maria Galdini Raimundo; DALGALARRONDO, Paulo.

Uma preciosidade da psicopatologia brasileira: 'A paranóia nos negros', de Raimundo NinaRodrigues. Revista Latinoamericana de Psicopatologia Fundamental, São Paulo, v.7, n.2. p.147-160. 2004.

ODA, Ana Maria Galdini Raimundo; DALGALARRONDO, Paulo.

Juliano Moreira: um psiquiatra negro frente ao racismo científico. Revista Brasileira de

Psiquiatria, São Paulo, v.22, n.4. Disponível em: http://www.scielo.br/scielo.php?script=s ci_arttext\&pid=S1516-44462000000400007. Acesso em: 18 set. 2010. 2000.

PAULA, Luis.

$O$ delírio nas histéricas. Tese apresentada à Faculdade de Medicina do Rio de Janeiro, Rio de Janeiro. 1889.

PORTOCARRERO, Vera.

Juliano Moreira e a metamorfose da psiquiatria brasileira. Conceito, Revista de Filosofia e Ciências do Homem, Lisboa, n.1, p.69-100. 2005.

ROCHA, Franco da.

O pansexualismo na doutrina de Freud. São Paulo: Typographia Brasil de Rothschild. 1920.

ROHDEN, Fabíola.

O império dos hormônios e a construção da diferença entre os sexos. História, Ciências, Saúde - Manguinhos, Rio de Janeiro, v.15, supl., p.133-152. 2008.
ROUDINESCO, Elizabeth; PLON, Michel. Dicionário de psicanálise. Rio de Janeiro: Jorge Zahar. 1998.

ROUDINESCO, Elizabeth.

História da psicanálise na França: a batalha dos cem anos, v.1:1885-1939. Rio de Janeiro: Jorge Zahar. 1989.

ROXO, Henrique.

Sexualidade e demência precoce. Archivos Brasileiros de Neuriatria e Psychiatria, Rio de Janeiro, v.1, n.1. p.337-349. 1919.

SILVA, A.S.

Higiene da primeira infância. Tese apresentada à Faculdade de Medicina do Rio de Janeiro, Rio de Janeiro. 1882.

TEIVE, Hélio et al.

Professor Antônio Austregésilo, o pioneiro da neurologia e do estudo dos distúrbios do movimento no Brasil. Arquivos de Neuropsiquiatria. São Paulo, v.57, n.3B. Disponível em: www.scielo.br/scielo.php?script= sci_arttext\&pid=S0004-282X1999000500030. Acesso em: 28 dez. 2009. 1999.

TRILLAT, Etienne.

História da histeria. São Paulo: Escuta. 1991.

VENANCIO, Ana Teresa A.

Doença mental, raça e sexualidade nas teorias psiquiátricas de Juliano Moreira. Physis: Revista de Saúde Coletiva, Rio de Janeiro, v.14, n.2. Disponível em: http://www.scielo.br/ scielo.php?script=sci_arttext\&pid=S0103$73312004000200006 \& \operatorname{lng}=$ pt\&nrm=iso. Acesso em: 12 set. 2010. 2004. 